\title{
BACK-EFFLUERAGE MASSAGE (BEM) TERHADAP NYERI DAN TEKANAN DARAH IBU BERSALIN KALA I
}

\author{
Halimatussakdiah \\ Jurusan Keperawatan Poltekkes Aceh \\ Email: atus_halimah@yahoo.com
}

\begin{abstract}
Effect of Back-Effleurage Massage (BEM) to Pain and vital sign changes in Women who childbirth at Stage I. Pain is unpleasant emotional and neurological experience, one feels that a treatment indispensable, labor pain causes mother to worry that they will not be able to pass through the birth process. This study were to determine the effect of Back-Effleurage Massage (BEM) to changes in pain and vital sign, before and after intervention of BEM in Women who childbirth at Stage I. This study was a quasi-experiment. Population were all of mother who childbirth stage I, active phase, in delivery room of Aceh Government Public Hospital. 30 mothers were taken with accidental sampling. The instruments were Numeric Rating Scale (NRS) and sphygmomanometer. Data were collected through guided interviews and analyzed by univariate and Bivariate with paired t-test. The result indicated that BEM can reduce pain intensity $\mathrm{p}=0,000$, change systolic blood pressure $p=0,000$, alter blood pressure diastolic, at the value of $p=0.0016$. The study concludes that BEM affects pain and vital sign of Women who childbirth at Stage I.
\end{abstract}

Keywords: Pain, Blod presure, Back Effluerage Massage

\begin{abstract}
Abstrak: Back-Effluerage Massage (BEM) terhadap Nyeri dan Tekanan DarahIbu Bersalin Kala I. Nyeri merupakan pengalaman emosional dan sensori yang tidak menyenangkan yan dirasakan seseorang sehingga sangat diperlukan penanganan. Nyeri persalinan menyebabkan ibu merasa khawatir tidak akan mampu melewati proses persalinan. Tujuan penelitian ini untuk mengetahui pengaruh Back Effluerage Massage (BEM) terhadap perubahan nyeri dan tanda-tanda vital ibu bersalin sebelum dan sesudah dilakukan intervensi Back Effluerage Massage. Jenis penelitian ini adalah Quasi experiment. Populasi pada penelitian ini adalah ibu bersalin kala I fase aktif di Ruang Bersalin Rumah Sakit Pemerintah Aceh, jumlah sampel 30 orang, pengambilan sampel secara teknik Accidental sampling. Alat pengumpulan data berupa Numeric Rating Scale (NRS) dan Spigmomanometer. Metode pengumpulan data dengan wawancara terpimpin. Analisa data menggunakan univariat dan bivariat: paired t-test. Hasil penelitian diketahui bahwa Back effluerage massage (BEM) dapat menurunkan intensitas nyeri pada ibu bersalin dengan nilai $p=0,000$, perbedaan tekanan darah sistole dengan nilai $p=0,000$, perbedaan tekanan darah diastol dengan nilai $p=0,016$. Kesimpulan penelitian terdapat pengaruh Back efflurage massage terhadap perubahan nyeri dan Tekanan Darah ibu pada persalinan kala I. Oleh karena itu, diharapkan kepada penolong persalinan agar memberikan teknik Back Effluerage Massage kepada ibu bersalin untuk meminimalkan rasa nyeri.
\end{abstract}

Kata kunci: Nyeri, Tekanan darah, Back Effluerage Massage

Perempuan sekitar $67 \%$ merasa khawatir, tentang nyeri persalinan (Sumarah dkk, 2009). Nyeri yang tidak di-manage secara baik akan berdampak pada proses persalinan (Mander, 2003). Nyeri yang menyertai kontraksi uterus memengaruhi mekanisme fisiologis sejumlah sistem tubuh yang selalu menyebabkan respons stress fisiologis yang menyeluruh pada ibu (Lestari I, 2012). Nyeri persalinan yang berat dan lama dapat memengaruhi ventilasi, sirkulasi, metabolisme, dan aktivitas uterus (Mander, 2003). Nyeri bersalin dapat menimbulkan respons fisiologis yang mengurangi kemampuan rahim berkontraksi, sehingga memperpanjang waktu persalinan (Bobak, 2004).
Nyeri yang dialami oleh ibu bersalin perlu dipertimbangkan, tentang bagaimana cara mengatasi nyeri tersebut (Bobak, 2004). Berdasarkan penelitian di Amerika Serikat 70\% sampai $80 \%$ ibu yang melahirkan mengharapkan persalinan berlangsung tanpa rasa nyeri. Berbagai cara dilakukan agar ibu melahirkan tidak selalu merasa nyeri dan merasa nyaman. Saat ini $20 \%$ hingga $50 \%$ persalinan dirumah sakit swasta di Indonesia dilakukan dengan operasi Caesar. Di Brazil angka section caesarea ini lebih dari 50\% dari angka kelahiran di suatu rumah sakit yang merupakan persentase tertinggi diseluruh dunia (Jayanthi, 2010). Trend/ kecenderungan para ibu memilih persalinan secara operasi Sectio 
Caesarea untuk menghindari nyerisaat melahirkan pervagina (Maryunani, 2010).

Cherkin, C. D. et al. (2011) mengatakan bahwa di Amerika Serikat, massage digunakan berbagai teknik pemijatan pada jaringan lunak yang bertujuan untuk mengubah cara pasien memahami dan menggunakan tubuh mereka untuk mengurangi nyeri. Tidak ada studi membandingkan efektivitas berbagai relaksasi dari massageyang berfokus pada mengoreksi kelainan jaringan lunak.Menurut WHO (2003), manajemen nyeri persalinan ada dua cara yang digunakan, yaitu secara farmakologis dan non farmakologis.

Tindakan farmakologis masih menimbulkan pertentangan karena pemberian obat selama persalinan dapat menembus sawar placenta dan berefek pada fetus selain juga berefek pada ibu. Metode non farmakologis tidak membahayakan bagi ibu maupun fetus, tidak memperlambat persalinan jika diberikan kontrol nyeri yang adekuat, dan tidak mempunyai efek alergi maupun efek negatif lain. Penanganan nyeri dengan non Farmakologi dapat dilakukan dengan

Back-Effluerage Massage (Massase pada punggung) yaitu merangsang titik tertentu di sepanjang meridian medulla spinalis yang ditransmisikan melalui serabut saraf besar ke formatio retikularis, thalamus dan sistem limbic tubuh akan melepaskan endorfin (Danuatmaja, 2008 dalam Rejeki S, 2013). Endorfin merupakan neurotransmitter atau neuromodulator yang menghambat pengiriman rangsang nyeri dengan menempel kebagian reseptor opiat pada saraf dan sumsum tulang belakang sehingga dapat memblok pesan nyeri ke pusat yang lebih tinggi dan dapat menurunkan sensasi nyeri (Maryunani, 2010).

Penelitian yang dilakukan oleh Sri Rejeki dengan judul "Tingkat Nyeri Pinggang Kala I Persalinan melalui Teknik Back-Effluerage dan Counter-Pressure" penelitian ini dilakukan di RSUD Ambarawa Kabupaten Semarang tahun 2013 bahwa setelah intervensi nyeri menurun dalam rentang skala 7-8 sebanyak 6 responden dengan persentase sebesar $25 \%$ dan menurun dalam rentang 3-6 sebanyak 18 responden dengan persentase sebesar $75 \%$. Penelitian lain tentang Pengaruh Deep back massase terhadap penurunan nyeri persalinan kala I fase aktif dan kecepatan pembukaan pada ibu bersalin primigravida diketahui 42 responden, ditemukan tingkat nyeri sangat berat pada kelompok yang dilakukan Deep back massage sebanyak 0\%, atau lebih sedikit pada kelompok kontrol sebanyak 4 orang $(19,1 \%)$. Kondisi sesudah perlakuan pada kedua kelompok adalah berbeda. Hal ini juga dibuktikan dari hasil uji Mann-Whitney didapatkan hasil $p=0,000<0,05$.

Hasil observasi yang dilakukan peneliti pada tanggal 2-8 Maret 2016 di Ruang Bersalin Rumah Sakit Pemerintah Aceh ditemukan 15 orang ibu bersalin, yang berteriak-teriak kesakitan karena nyeri yang dirasakan pada kala I dan II sekitar 11 orang sedangkan 4 orang ibu hanya sekedar menahan nyeri dan sabar dengan keadaan nyeri pada kala I dan II yang dirasakan. Tetapi penolong persalinan menganggap hal itu merupakan alamiah dirasakan oleh setiap ibu bersalin, dan penolong tidak melakukan penanganan nyeri secara non farmakologis seperti Back-Effluerage Massage (BEM).

Berdasarkan uraian di atas penulis merasa tertarik untuk melakukan penelitian mengenai "Bagaimanakah pengaruh $B E M$ terhadap nyeri dan Tekanan darah ibu bersalin kala I di Ruang Bersalin Rumah Sakit Pemerintah Aceh?"

Penelitian ini bertujuan untuk mengidentifikasi perbedaan nyeri persalinan dan perbedaan tekanan darah kala I sebelum dansesudah dilakukan BEM di ruang Bersalin RumahSakit Pemerintah Aceh. Adapun manfaat penelitian ini antara lain yaitu untuk: 1) Pengembangan ilmu pengetahuan berupa masukan yang bermanfaat tentang cara penurunan nyeri non Farmakologis dan pengawan Tekanan Darah ibu bersalin kala I dan 2) Pegembangan riset-riset keperawatan maternitas terkait nyeri Persalinan.

\section{METODE PENELITIAN}

Jenis penelitian ini adalah quasi eksperimen. Tujuannya adalah mengidentifikasi perbedaan nyeri persalinan kala I dan perbedaan Tekanan Darah sebelum dan sesudah dilakukan Back-Effluerage Massage di ruang Bersalin Rumah Sakit Pemerintah Aceh. Desain penelitian yang digunakan adalah one group pretest posttest dengan populasi adalah ibu yang menjalani persalinan kala I fase aktif yang berjumlah 224 orang. Teknik pengambilan sampel menggunakan purposive sampling dengan jumlah sampel 30 . Tempat penelitian dilakukan di Rumah Sakit Pemerintah Aceh (Rumah Sakit Ibu dan Anak dan Rumah Sakit Umum Meuraxa) pada Tahun 2016. Lembar isian merupakan alat untuk mengukur tingkat intensitas nyeri dan Tekanan Darah ibu. Instrument yang dipakai adalah skala nyeri visual dan Spigmomanometer. Pengumpulan data dilakukan 10 hari pada tanggal 12 Juli 2016 sampai 21 juli 2016. Uji statistik yang digunakan adalah dependent $t$-test (paired $t$-test). 
HASIL

\section{A. ANALISIS UNIVARIAT}

Tabel 1. Distribusi Data Demografi Responden

\begin{tabular}{lrr}
\hline \multicolumn{1}{c}{ Kategori } & f & \% \\
\hline Umur : & & \\
$<20$ tahun & 2 & 6,7 \\
20-35 tahun & 24 & 80 \\
$>35$ tahun & 4 & 13,3 \\
\hline Pekerjaan : & & \\
Bekerja & 6 & 20 \\
Tidak bekerja & 24 & 80 \\
\hline Gravida : & & \\
Primigravida & 7 & 23,3 \\
Multigravida & 23 & 76,7 \\
\hline Total & 30 & 100 \\
\hline
\end{tabular}

Berdasarkan tabel 1 dapat dilihat bahwa sebagian besar responden berada pada usia 20-35 tahun sebanyak 24 responden ( $80 \%$ ), berdasarkan pekerjaan, responden yang tidak bekerja sebanyak 24 orang $(80 \%)$, dan berdasarkan gravida: multigravida sebanyak 23 orang $(76,7 \%)$.

\section{B. ANALISIS BIVARIAT}

1. Perbedaan Nyeri Responden Sebelum dan Sesudah Dilakukan Back Effluerage Massage (BEM)

Tabel 2. Perbedaan Nyeri Responden Sebelum dan Sesudah Dilakukan BEM

\begin{tabular}{lrrrr}
\hline $\begin{array}{c}\text { Perbedaan } \\
\text { Nyeri }\end{array}$ & Mean & $\begin{array}{c}\text { Std. } \\
\text { Deviasi }\end{array}$ & T & $\begin{array}{c}\boldsymbol{p} \text { - } \\
\text { value }\end{array}$ \\
\cline { 1 - 3 } Sebelum & 9,26 & 0,69 & 19,38 & 0.00 \\
\cline { 1 - 3 } Seudah & 0,69 & 0,66 & & \\
\hline
\end{tabular}

Berdasarkan tabel 2 diketahui bahwa terdapat perbedaan nilai rata-rata skala nyeri ibu bersalin sebelum dan sesudah intervensi yaitu: pada sebelum adalah 9,26 dengan standar deviasi 0,69 dan sesudah menjadi 06,90 dengan standar deviasi 0,66. Terlihat nilai mean perbedaan sebelum dan sesudah adalah 2,36 dengan standar deviasi $0,66(p=0,000)$.

\begin{tabular}{|c|c|c|c|c|}
\hline $\begin{array}{r}\text { Tabel 3. Per } \\
\text { Re } \\
\text { Dil }\end{array}$ & $\begin{array}{l}\text { aan } \\
\text { den } \\
\operatorname{kan} B E\end{array}$ & $\begin{array}{l}\text { Tekanan } \\
\text { elum dan }\end{array}$ & $\begin{array}{r}I \\
\text { Ses }\end{array}$ & $\begin{array}{l}\text { rah } \\
\text { dah }\end{array}$ \\
\hline $\begin{array}{c}\text { Perbedaan } \\
\text { tekanan } \\
\text { darah }\end{array}$ & Mean & $\begin{array}{c}\text { Std. } \\
\text { Deviasi }\end{array}$ & $T$ & $\begin{array}{c}p- \\
\text { value }\end{array}$ \\
\hline $\begin{array}{l}\text { Sistole } \\
\text { sebelum }\end{array}$ & 131,33 & 8,99 & 6,39 & 0.00 \\
\hline $\begin{array}{l}\text { Sistole } \\
\text { Sesudah }\end{array}$ & 124,33 & 8,68 & & \\
\hline
\end{tabular}

Berdasarkan tabel 3 diketahui bahwa terdapat perbedaan nilai rata-rata tekanan darah sistole ibu bersalin sebelum dan sesudah intervensi yaitu pada pretest adalah 131,33 dengan standar deviasi 8,99 dan post test menjadi 124,33 dengan standar deviasi 8,68. Terlihat nilai mean perbedaan sebelum dan sesudah adalah 7,00 dengan standar deviasi 5,99 $(p=0,00)$.

\begin{tabular}{|c|c|c|c|c|}
\hline \multicolumn{3}{|c|}{$\begin{array}{l}\text { Perbedaan Tekanan } \\
\text { Responden Sebelum } \\
\text { Dilakukan BEM }\end{array}$} & \multicolumn{2}{|c|}{$\begin{array}{l}\text { Darah Diastole } \\
\text { dan Sesudah }\end{array}$} \\
\hline $\begin{array}{c}\text { Perbedaan } \\
\text { tekanan } \\
\text { darah }\end{array}$ & Mean & $\begin{array}{c}\text { Std. } \\
\text { Deviasi }\end{array}$ & $\mathbf{T}$ & $\begin{array}{c}p- \\
\text { value }\end{array}$ \\
\hline $\begin{array}{l}\text { Diastole } \\
\text { sebelum }\end{array}$ & 84,30 & 6,10 & 2,557 & 0.00 \\
\hline $\begin{array}{l}\text { Diastole } \\
\text { Sesudah }\end{array}$ & 82,66 & 5,20 & & \\
\hline
\end{tabular}

Berdasarkan tabel 4 diketahui bahwa terdapat perbedaan nilai rata-rata tekanan darah diastole ibu bersalin sebelum dan sesudahintervensi yaitu pada sebelum adalah 84,30 dengan standar deviasi 6,10 dan sesudah menjadi 82,66 dengan standar deviasi 5,20. Terlihat nilai mean perbedaan sebelum dan sesudah adalah 1,63 dengan standar deviasi 3,49 $(p=0,016)$

\section{PEMBAHASAN}

1. Perbedaan Nyeri pada Ibu Bersalin Sebelum dan Sesudah dilakukan BEM

Perbedaan hasil ukur skala nyeri sebelum dan sesudah dilakukan Back Effluerage Massage dapat dilihat di tabel 2. Hasil analisa menunjukkan bahwa ada perbedaan nilai nyeri sebelum dansesudah dilakukan BEM yang menggunakan paired t-test dengan nilai $\alpha 0,05$ dan $(p=0,000)$. Hal ini dapat diartikan ada perbedaan skala nyeri sebelum dan sesudah dilakukan BEM pada Ibu Bersalin di Ruang Bersalin Rumah Sakit Pemerintah Aceh.

Nyeri merupakan pengalaman pribadi dan bersifat subjektif, berbeda antara satu orang dengan orang lain dan dapat juga berbeda pada orang yang sama di waktu berbeda (Nesson, 2003 $\&$ Reeder, 2013). Rasa nyeri muncul akibat respons psikis dan refleks fisik. Kualitas rasa nyeri fisikdinyatakan sebagai nyeri tusukan, nyeri terbakar, rasa sakit, denyutan, rasa mual dan peningkatan aktivitas sistem saraf simpatik timbul sebagai respons terhadap nyeri dan dapat mengakibatkan perubahan Tekanan Darah, denyut nadi dan pernafasan (Bobak, 2004). Nyeri sesudah dilakukan BEM merupakantingkat nyeri 
yang dirasakan oleh ibu bersalin sesudah diberikan Intervensi BEM.

Efek terapi massase yang di berikan pada tubuh termasuk BEM akan menimbulkan, yaitu: 1) menentukan perubahan fisiologis, lebih objektif (misalnya, denyut jantung, tekanan darah, dan kadar kortisol) dan psikologis, 2) perubahan yang lebih subjektif (misalnya, suasana hati, kesejahteraan, dan stres). Kategori yang lain adalah berdasarkan efek spesifik vs non-spesifik. Efek tertentu yang dimaksudkan oleh tindakan mekanik dari terapi seperti, penurunan rasa nyeri, meningkatkan jangkauan gerak, dan relaksasi otot (Kaptchuk, 2002; Koshi, \& Pendek, 2007 dalam Boulanger, K.T. 2012).

Pada penelitian ini setelah diberikan $B E M$ terjadi penurunan intensitas nyeri.Hal ini menunjukkan adanya perubahan intensitas nyeri sesudah diberikan intervensi $B E M$ sehingga pemberian intervensi ini dapat membantu terhadap penurunan intensitas nyeri pada saat persalinan. Metode non farmakologis tidak membahayakan bagi ibu maupun fetus, tidak memperlambat persalinan jika diberikan kontrol nyeri yang adekuat. Penanganan nyeri dengan Non Farmakologi salah satu caya yang dapatdilakukan dengan $B E M$ yang dapat merangsang titik tertentu di sepanjang meridian medullaspinalis yang ditransmisikan melalui serabut saraf besar ke formation retikularis, thalamus dan sistem limbic di otak. Hal ini akan menyebabkan tubuh melepaskan hormon endorphin (Danuatmaja, 2004 dan Rejeki S, 2013). Endorfin merupakan neurotransmitter yang menghambat pesan nyeri ke pusat yang lebih tinggi dan dapat menurunkan sensasi nyeri (Maryunani, 2010).

Hal ini sejalan dengan penelitian yang dilakukan oleh Maita (2016) mengenai pengaruh Massage Effluerage terhadap pengurangan tingkat nyeri persalinan kala I fase aktif pada Primigravida. Hasilnya menunjukkan bahwa rata-rata tingkat nyeri persalinan sebelum massage effluerage yaitu 3,78 (nyeri berat) dan rata-rata nyeri persalinan sesudah massage effluerage yaitu 2,96 (nyeri sedang). Nilai $p$-value $=0,000$ yang berarti lebih kecil dari $\alpha 0,05$ $(0,000 \leq 0,05)$. Demikian halnya dengan penelitian Aryani (2015), tentang pengaruh massase pada punggung terhadap intensitas nyeri kala I persalinan normal menunjukkan bahwa intensitas nyeri ibu bersalin normal kala I pada kelompok di massage lebih rendah dibandingkan dengan kelompok yang tidak di massage. Perbedaan tersebut sebesar 29,62 point ( $p$-value 0,001).

Teknik Back-Effleurage dan teknik Counter-Pressuretelah di uji perbedaanya terhadap tingkat nyeri pinggang kala I fase aktif persalinan dengan nilai $p(0,046<0,05)$. Dari kedua teknik tersebut yang lebih efektif dalam mengurangi nyeri pinggang persalinan dengan hasil nilai mean 3,63>mean teknik Back-Effleurage 2,92 dengan menggunakan Uji Mann-Whitney ( Al-Maqassary, 2012).

Menurut peneliti, adanya pengaruh $B E M$ terhadap nyeri persalinan karena merupakan teknik yang dapat meminimalkan rasa nyeri persalinan karena dapat merilekskan ketegangan otot yang merangsang nyeri dan pada saat melakukan $B E M$ responden bernapas perlahan sehingga responden merasa nyaman dan dapat mengalihkan perhatiannya terhadap nyeri. Terapi $B E M$ juga dapat merangsang hormon endorfin yang bias meminimalkan rasa nyeri persalinan dan juga dapat membuat tanda-tanda vital dalam keadaan terkontrol. Sehingga ibu bersalin dapat menjalani persalinan dengan tenang dan lancar.

\section{Perbedaan Tekanan Darah Ibu Bersalin Sebelum dan Sesudah BEM}

Perbedaan hasil ukur tekanan darah sebelum dan sesudahdilakukan BEM dapat dilihat di tabel 3.Hasil analisa menunjukkan bahwa ada perbedaan nilai tekanan darahsistole sebelum dan sesudah dilakukan BEM. Hasil analisa variabel tekanan darah sistole dan diastole diperoleh hasil yang signifikan $(p=0,000)$. Hal yang sama tekanan ditemukan pada Tekanan darah diastole diperoleh hasil yang signifikan $(0,016)$. Hal ini dapat diartikan ada perbedaan tekanan darah systole dan diastole sebelum dan sesudah dilakukan Back efflurage massage pada Ibu Bersalin DiruangBersalin Rumah Sakit Pemerintah Aceh.

Nyeri persalinan yang berat dan lama dapat mempengaruhiventilasi, sirkulasi, metabolisme, dan aktivitas uterus (Mander, 2003). Pada setiap kontraksi, $400 \mathrm{ml}$ darah dikeluarkan dari uterusdan masuk ke dalam sistem vaskuler ibu. Hal ini akan meningkatkan curah jantung sekitar $10 \%$ sampai $15 \%$ pada tahap kedua persalinan. Ada beberapa faktor yang mengubah tekanan darah ibu. Aliran darah, yang menurun pada arteri uterus akibat kontraksi, diarahkan kembali ke pembuluh darah perifer. Timbul tahanan perifer, tekanan darah meningkat, dan frekuensi denyut nadi melambat. Pada tahap pertama persalinan, kontraksi uterusmeningkatkan tekanan sistolik sampai sekitar $10 \mathrm{mmHg}$ (Bobak, 2004).

Aplikasi Pijat (massage) akan mengurangi kecemasan, tekanan darah, dan detak jantung tetapi tidak suasana hati yang negatif, dapat dilakukan penilaian langsung dari rasa sakit, dan tingkat kortisol. Pengurangan kecemasan sifat 
dan depresi adalah efek terbesar terapi massase. Pengobatan alternatif ini memberikan manfaat yang sama besarnya dengan yang psikoterapi (Moyer, 2004).

Penelitian yang yang dilakukan Chen., et all (2013), ditemukan responden yang mempunyai sistolik Blood Pressure (BP) ditemukan $(\mathrm{F}(3,189=18,91, p<0,01)$, diastolik $\mathrm{BP}(\mathrm{F}(3,189)=13,40, p<0,01)$, denyut jantung $(\mathrm{F}$ $(3,189)=26.28, p<0,01)$, dan tingkat pernapasan (F $(3,189)=5,77, \quad p<0,01)$ secara signifikan menurun setelah kembali pijat. tingkat kejenuhan oksigen menunjukkan peningkatan yang signifikan $(\mathrm{F}(3,189)=42,82, p<0,01)$. peserta laki-laki mengungkapkan penurunan lebih signifikan dalam kecemasan dari peserta perempuan $(\mathrm{F}(1,50)=7.27, p=0,01)$. Mereka dengan gagal jantung yang lebih berat dan lebih besar dari tingkat kecemasan $(\mathrm{F}(2,61)=4,31, p=$ $0,02)$ dan tekanan darah sistolik $(\mathrm{F}(2,61)=3,86$, $p=0,03)$ menunjukkan respon signifikan lebih besar untuk kembali pijat.

Hal ini sejalan dengan penelitian yang dilakukan oleh Dewi (2015) tentang Hubungan Counterpressure dengan nyeri persalinan pada ibu bersalin kala I fase aktif ibu primipara dengan sampel 32 responden yang menunjukkan bahwa 11 ibuyang tidak dilakukan Counterpressure, terdapat sebanyak $8(72,7 \%)$ mengalami nyeri berat dan $3(27,3 \%)$ nyeri ringan, sedangkan ibu yang melakukan Counterpressure sebanyak 21 responden, dimana responden mengalami nyeri ringan sebesar $14(66,7 \%)$ dan nyeri berat sebanyak 7 (33,3\%). Hasil tersebut menunjukkan ada hubungan Counterpressure dengan nyeri persalinan pada ibu bersalin kala I fase aktif ibu primipara $(p$-value $=0,034)$.

Menurut peneliti ada pengaruh BEM terhadap perubahan nyeri pada ibu bersalin karena BEM merupakan suatu tindakan non farmakologi untuk mengurangi nyeri. Apabila nyeri berkurang maka tekanan darah akan stabil karena kondisi ibu lebih tenang sehingga kontraksi jantung lebih stabil dan tidak terjadi peningkatan kardiak output.

Menurut peneliti fakto-faktor yang mempengaruhi hasil penelitian ini mempunyai perbedaan hasil sebelum dan sesudah intervensi karena faktor-faktor demografi responden seperti usia responden berada pada usia baik untuk usia reproduksi yaitu 20-35 tahun sebanyak 24 orang
(80\%), faktor pekerjaan responden sebagian pada katagori tidak bekerja sebanyak 24 orang (80\%), dan faktor kehamilan berada pada kondisi hamil lebih dari 1 kali (multigravida) sebanyak 23 orang $(76,7 \%)$.

Faktor-faktor demografi yang di temukan pada responden sangat membantu kegiatan intervensi BEM karena selama observasi dan selama pengumpulan data, responden kooperatif dengan intervensi yang di berikan dan meminta di lakukan berulang-ulang pada peneliti.Tindakan BEM di ajarkan kepada keluarga pendamping dan responden terlihat tenang pada ekpresi wajah dan perfoma tubuhnya. Selain itu ada faktor lain yang sangat mendukung dilakukan BEM karena dukungan keluarga seperti suami, mertua dan anggota keluarga lain yang melakuukan BEM, sehingga hasil penelitian ini menghasilkan perbedaan sebelum dan sesudah intervensi.

\section{SIMPULAN}

1. Terdapat perbedaan nyeri ibu bersalin sebelum dan sesudah dilakukan Back effluerage massage pada ibu bersalin dengan nilai $p$-value $(0,000)<\alpha(0,05)$.

2. Terdapat perbedaan Tekanan darah sistole dan diastole ibu bersalin sebelum dan sesudah dilakukan BEM pada Ibu Bersalin dengan tekanan darah sistole nilai $p$-value $(0,000)$ dan tekanan darah diastole nilai p-value $(0,016)$

\section{SARAN}

Saran dari hasil penelitian ini ditujukan kepadaPerawat dan Bidan diruang bersalin rumah sakit ibu dan anak dan rumah sakit umum Meuraxa kota Banda Aceh untuk mempraktikkan Back efflurage massage terhadap ibu bersalin pada persalinan kala I, bagi institusi pendidikan keperawatan, agar dapat meningkatkan pengetahuan dan keterampilan mahasiswa tentang BEM dengan membuat SOP BEM di laboratorium Keperawatan Maternitas, serta bagi peneliti selanjutnya, disarankan untuk memperdalam tentang Efektifitas BEM dan Relaksasi pernafasan terhadap penurunan Nyeri Persalinan kala I.

\section{Daftar Pustaka}

Al-Maqassary. 2012. Perbedaan Efektifitas Teknik Back-Effluerage dan teknik
Counter-Pressure terhadap Tingkat Nyeri Pinggang Kala I Fase Aktif Persalinan di 
RSUD Ambarawa Semarang. jpkeperawatandd120016 (Diakses pada 24 Januari 2017).

Aryani Y, Masrul, Evareny, L. 2015. Pengaruh Masase pada Punggung terhadap Intensitas Nyeri Kala I Fase Laten Persalinan Normal Melalui Peningkatan Kadar Endorfin Jurnal.fk.unand.ac.id (Diakses pada 24 Januri 2017).

Bobak. 2004. Buku Ajar Keperawatan Maternitas. Jakarta: EGC.

Chen., et al. 2013. Effect of Back Massage Intervention on Anxiety, Comfort, and Physiologic Responses in Patients with Congestive Heart Failure. Journal of Alternative and Complementary Medicine, May; $19(5)$ : 464-470. doi: 10.1089/acm.2011.0873 (Diakses pada 24 Januari 2017).

Boulanger, K.T. 2012. Factors related to satisfaction, pain and affect outcomes in Massage Therapy clients. Philosophy Degree in Community and Behavioral Health in The Graduate College of The University of Iowa.Published by ProQuest LLC (2015) (Diakses pada 24 Januari 2017).

Cherkin, C. D et. al. 2011. A comparison of the effects of 2 types of massage and usual care on chronic low back pain: a randomized, controlled trial. Ann Intern Med, volume 155

https://www.ncbi.nlm.nih.gov (Diakses pada 24 Januari 2017).

Dewi, Y dan Evasantriani. 2015. Hubungan Counter Pressure dengan Nyeri Persalinan pada Ibu Bersalin Kala I Fase Aktif Ibu Primipara. Jurnal Kebidanan, Vol 1, No 1, Februari 2015: 9-12 (Diakses pada 24 Januari 2017).
Danuatmaja. 2004. Persalinan Normal Tanpa Rasa Sakit. Jakarta: Puspa Swara.

Jayanthi. 2010. Teknik Relaksasi Napas Dalam. $\mathrm{http} /$ /rentalhikari.worlpress.com (Diakses pada 1 Februari 2016).

Lestari, I. 2012. Pengaruh Deep Back Massage terhadap Penurunan Nyeri Persalinan Kala I Fase Aktif dan Kecepatan Pembukaan pada Ibu Bersalin Primigravida (Diakses pada tanggal 3 Januari 2016).

Maita, L. 2016. Pengaruh Deep Back Massage terhadap Penurunan Nyeri Persalinan. Jurnal Ilmiah Kesehatan, Vol. 9, No. 2, Agustus 2016, hal 186-190.

Mander, R. 2003. Nyeri Persalinan. Jakarta: EGC.

Maryunani. 2010. Nyeri dalam Persalinan "Teknik dan Cara penanganannya". Jakarta: TIM.

Moyer, Christopher A. Rounds, Hannum \& James W.A. 2004. Meta-Analysis of Massage Therapy Research. Psychological Bulletin, Vol 130 (1), Jan 2004, 3-18.

Neesson, J.D. \& May, K.A. 2003.Comprehensive maternity nursing; nursing process and the childbearing family. Philadelphia: J.B Lippincott Company.

Reeder, S.J., Martin, L.L \& Griffin, D.K. 2013. Maternity Nursing; Family Newborn and Women's Health Care. Philadelphia: Lippincott.

Sri Rejeki. 2013. Tingkat Nyeri Pinggang Kala I Persalinan melalui Teknik Back-Effluerage dan Counter-Pressure. http://jurnal.unimus.ac.id (Diakses pada tanggal 3 januari 2016).

Sumarah. 2009. Perawatan Ibu Bersalin. Yogyakarta: Fitramaya.

WHO. 2003. Perawatan Ibu dan Bayi: Pedoman Praktis. Jakarta: EGC. 